\title{
Visceral Adiposity Index was Independently Associated with Hyperuricemia in Patients with Polycystic Ovary Syndrome
}

Chen Yun ( $\square$ chenyun354@163.com )

Fujian Medical University https://orcid.org/0000-0003-2933-0807

Han Yan

Xiamen University

Yang Hongyi

The First Affiliated Hospital of Xiamen University

Ma Danyan

Xiamen University

Zeng Xiying

Fujian Medical University

\section{Ye Jiawen}

Fujian Medical University

Chen Zheng

The First Affiliated Hospital of Xiamen University

\section{Zheng Xin}

The First Affiliated Hospital of Xiamen University

\section{Yan Xiaohong}

The First Affiliated Hospital of Xiamen University

\section{Liu Changqin}

The First Affiliated Hospital of Xiamen University

\section{Research}

Keywords: Visceral adiposity index, polycystic ovary syndrome, hyperuricemia, serum uric acid, obesity indicators.

Posted Date: February 4th, 2021

DOI: https://doi.org/10.21203/rs.3.rs-173675/v1

License: (c) (1) This work is licensed under a Creative Commons Attribution 4.0 International License. Read Full License 


\section{Abstract}

Objective: The current study aimed to explore the prevalence rate of hyperuricemia in women with polycystic ovary syndrome (PCOS) and investigate the relationship between Visceral adiposity index (VAI) and hyperuricemia in PCOS.

Methods: In this cross-sectional study, 318 PCOS women were evaluated between November 2018 to September 2020. Of them, 256 subjects with complete anthropometric and SUA data were analyzed. Multivariable linear regression and logistic regression analyses were performed to determine the associations of VAI with the SUA level and hyperuricemia.

Results: The prevalence rate of hyperuricemia was $56.3 \%$ in women with PCOS and was gradually increased across tertiles of VAl, which was $2.6 \%, 21.3 \%, 22.4 \%$, respectively. Obese subjects had significantly higher levels of systolic blood pressure (SBP), waist circumference (WC), hip circumference $(\mathrm{HC})$, waist-to-hip ratio (WHR), body fat percentage (BFP), triglycerides (TG), low-density lipoprotein cholesterol $(L D L-C), \operatorname{VAl}(P<0.001)$ and lower high-density lipoprotein cholesterol $(H D L-c)(P<0.001)$. Pearson correlation analysis showed the SUA level was positively correlated with BMI, BFP, WHR, log (TG), $\log (\mathrm{LDL}-\mathrm{C})$, SBP, and log (VAI) and negatively correlated with HDL-c. In addition, with adjustment for potential confounding factors, multivariable linear regression and logistic regression analyses showed that VAI significantly associated with the SUA level and hyperuricemia, with the coefficient (95\% confidence interval $(\mathrm{Cl}))$ of $9.20(2.85-15.56, \mathrm{P}=0.005)$ and the adjusted odds ratio $(95 \% \mathrm{Cl})$ of $1.32(1.05-$ $1.65, P=0.018)$, respectively.

Conclusion: The present study indicates that VAI was independently associated with hyperuricemia, even with adjustment for BMI and other potential confounding factors.

\section{Introduction}

Polycystic ovary syndrome (PCOS) is a common endocrine and metabolic disease affecting up to $21 \%$ of reproductive-age women[1]. Women with PCOS accompanying with metabolic disorders such as insulin resistance (IR), abdominal obesity, obesity, hyperuricemia, dyslipidemia and abnormal glucose[2]. The prevalence of obesity in women with PCOS is about $30 \%$ 70\%, and obesity can worsen metabolic disorders in PCOS patients[3].

Guidelines for the management of hyperuricemia and gout highlighted the benefits of weight loss for overweight / obese patients[4]. Previous studies have developed a number of weight management indices, including body mass index (BMI), waist circumference (WC), waist-to-hip ratio (WHR) and body fat percentage (BFP). BMI and WC are the common measurements used to identify obesity in clinical practice and have been demonstrated as predictors of metabolic and Cardiovascular diseases (CVDs), but they cannot completely distinguish between visceral adipose tissue and subcutaneous adipose tissue[5]. Studies have shown that there is a stronger correlation between the SUA level and visceral adipose tissue[6]. In recent years, as an indicator of the function of visceral adipose tissue, Visceral 
adiposity index (VAl) has been introduced to reflect metabolic abnormalities[7]. VAl is a model that can be easily calculated by both anthropometric (BMI and WC) and laboratory (triglycerides (TG) and highdensity lipoprotein cholesterol (HDL-C)) parameters. It has been demonstrated as a novel and accurate indicator of visceral fat distribution[8]. Moreover, studies have shown that the VAl has high accuracy in predicting metabolic disease such as IR, Type 2 Diabetes Mellitus (T2DM) and prediabetes[9-11].

Among those metabolic disorders in patients with PCOS, a growing evidence suggested that hyperuricemia was closely related to obesity $[1,12]$. Hyperuricemia is a disease of impaired uric acid metabolism. A recent study indicated that the prevalence of hyperuricemia in PCOS women is more than $25 \%$, while $58.75 \%$ of obese PCOS women approximately suffer from hyperuricemia, which was almost three folds higher than that in PCOS women with normal BMI[13]. Elevated SUA level not only increased the risk of gout, but also increased cardiovascular risk by promoting inflammation, oxidative stress and proliferation in PCOS women[14]. Also, hyperuricemia put PCOS women at a higher risk of fetal outcome and adverse maternal events [15]. Therefore, although it is unclear whether the SUA level is a cause or risk factor for obesity, we ought to pay more attention to women with high uric acid levels, especially obese PCOS women. However, there are limit studies on the association between visceral adipose tissue and hyperuricemia in women with PCOS, in which there have been some contradictory views $[16,17]$. Therefore, the objective of the present study was to explore the relationship between VAI and hyperuricemia in women with PCOS.

\section{Materials And Methods}

\section{Study population [}

The cross-sectional study was carried out at Department of Endocrinology and Diabetes, the First Affiliated Hospital of Xiamen University, Xiamen, China, from November 2018 to September 2020. A total of 318 patients aged from 18 to 40 years with PCOS were screened in this study. Of 318 PCOS patients, a total of $256(80.5 \%)$ with serum urate data were left for further analysis. The diagnosis of PCOS is based on Rotterdam criteria[18], which has been detailed described in our previous report[19]. The ethics committee of the First Affiliated Hospital of Xiamen Medical University approved this study protocol and written informed consent was obtained from each participant.

\section{Anthropometric and Laboratory Measurements}

The socio-demographic status included age, medical history and drug use, smoking and drinking, etc. All clinical, anthropometric and laboratory indicators were measured by a properly trained healthcare workers following standardized protocols and performed as described in the previous report[19]. Height, WC, Hip circumference $(\mathrm{HC})$ and body weight were measured by using a calibrated scale with lightweight clothing. The analysis of BFP was performed using bioelectrical impedance analysis (Tanita BC-420MA; Tanita, Tokyo, Japan). This analyzer is a simple and validated method for assessing body composition[20]. After sitting quietly for at least 15 minutes, the participants measured their blood pressure (BP) using an Omron electronic sphygmomanometer ((OMRON Healthcare)). 
All subjects received blood testing for reproductive hormonal and metabolic parameters in the morning after an overnight fast of at least 12-hour. All biochemical measurements were tested in the central laboratory of the First Affiliated Hospital, Xiamen University. Total cholesterol [6], TG, HDL-c were determined on a HITACHI 7450 analyzer. SUA level and creatinine were measured by the autoanalyzer (COBAS INTEGRA 400 plus, Roche, Basel, Switzerland). Testosterone (T) were quantified using chemiluminescent immunoassay analysis (SIEMENS ADVIA Centaur XP Immunoassay System; Siemens Healthcare Diagnostics Inc.).

\section{Calculation and definition of indexes}

Anthropometric indices were calculated using the following equation: $\mathrm{BMI}=$ weight $[\mathrm{kg}] /(\text { height }[\mathrm{m}])^{2}$;

The WHR $=\mathrm{WC}[\mathrm{cm}] / \mathrm{HC}[\mathrm{cm}]$; and VAl =

$$
\mathrm{VAI}=\left[\frac{W C[\mathrm{~cm}]}{(36.58+1.89 \times \mathrm{BMI})}\right] \times \quad\left(\frac{\mathrm{TG}[\mathrm{mmol} / \mathrm{l}]}{0.81}\right) \times\left(\frac{1.52}{\mathrm{HDL}-\mathrm{c}[\mathrm{mmol} / \mathrm{l}]}\right)
$$

The glomerular filtration rate (eGFR) was estimated using the following formula: eGFR $\left(\mathrm{mL} / \mathrm{min} / 1.73 \mathrm{~m}^{2}\right)$ $=175 \times \mathrm{Scr}(\mathrm{mg} / \mathrm{dL})^{-1.234} \times$ age $(\text { year })^{-0.179} \times 0.79[22]$.

Hyperuricemia was defined as the SUA level exceeding $360 \mu \mathrm{mol} / \mathrm{L}(6 \mathrm{mg} / \mathrm{dl})$ in women[23]. BMI categories were defined as normal weight $\left(\mathrm{BMI}<24 \mathrm{~kg} / \mathrm{m}^{2}\right)$, overweight $\left(24 \leq \mathrm{BMl}<28 \mathrm{~kg} / \mathrm{m}^{2}\right)$ and general obesity $\left(\mathrm{BMI} \geq 28 \mathrm{~kg} / \mathrm{m}^{2}\right)[24]$. And abdominal obesity was defined as a $\mathrm{WC} \geq 80 \mathrm{~cm}$ for females[24].

\section{Statistical analyses}

Skewness and kurtosis tests for normality. Data was presented as the mean \pm standard deviation (SD) or as median (inter-quartile range, IQR) for continuous variable or number and percentage for categorical variable. All subjects were stratified by the BMI and the SUA level, respectively. Differences between two groups were analyzed on continuous variables using the Student's $t$ test for those with normal distribution and Mann-Whitney $U$ test for those with skewed distribution and on categorical variables using chi-square test. Differences between the three groups were analyzed on continuous variables using one-way ANOVA for those with normal distributions and Kruskal-Wallis test for those with skewed distributions and on categorical variables using chi-square test.

Pearson's correlation analysis was used to analysis the correlation of the SUA level with age, Systolic blood pressure (SBP), diastolic blood pressure (DBP), BMI, WHR, lipid profiles, BFP, T(log-transformed), and VAl (log-transformed). Stepwise multivariable linear regression was used to assess the association between various factors associated with SUA. Multivariable linear regression was used to explore the association of VAI with SUA. And multivariable logistic regression analysis was used to calculate the adjusted odds ratios (OR) and 95\% confidence interval (Cl) of VAl for hyperuricemia in different models with adjustment for potential confounders. For both the multivariable linear regression and logistic regression analyses, model 1 was adjusted for age and occasional drinking. SBP, DBP, and eGFR were adjusted for in model 2; TC, LDL-C, T, and BMI were further adjusted for in model 3. All p-values were two- 
sided and $p$-value $<0.05$ was considered statistically significant. All statistical analyses were performed using SPSS version 21.0 software (IBM Corporation, Armonk, NY).

\section{Results}

After excluding 62 participants without SUA data, 256 PCOS patients were included in this study. The mean ( \pm SD) of SUA was $376.84 \pm 87.95 \mu \mathrm{mol} / \mathrm{L}$ for all subjects and their media (IQR) of age was 27.5 $(24.3-31.0)$ years old. The prevalence rate of hyperuricemia was $56.3 \%$, with the mean $( \pm$ SD) of SUA $438.91 \pm 58.95 \mu \mathrm{mol} / \mathrm{L}$. Patients with hyperuricemia had higher BMI and VAI (Table 1), and with the increase of BMI and VAl, the level of SUA and the prevalence of hyperuricemia also increased (Table 2, Fig. 1). 
Table 1

Anthropometric information and biochemical characteristics in women with PCOS.

\begin{tabular}{|c|c|c|c|c|}
\hline & all & Normouricemia & Hyperuricemia & $\begin{array}{l}\mathrm{p} \\
\text { value }\end{array}$ \\
\hline $\mathrm{n}$ & 256 & $112(43.7 \%)$ & $144(56.3 \%)$ & \\
\hline Age (years) & $27.5(24.3-31.0)$ & $28.0(25.0-30.8)$ & $27.0(24.0-31.0)$ & 0.877 \\
\hline $\begin{array}{l}\text { Occasional drinking ( } \mathrm{n} \text {, } \\
\% \text { ) }\end{array}$ & $23(8.98 \%)$ & $7(6.25 \%)$ & $16(11.11 \%)$ & 0.179 \\
\hline $\mathrm{SBP}(\mathrm{mmHg})$ & $118 \pm 12$ & $116 \pm 11$ & $120 \pm 13$ & 0.013 \\
\hline $\mathrm{DBP}(\mathrm{mmHg})$ & $80 \pm 10$ & $79 \pm 9$ & $80 \pm 11$ & 0.197 \\
\hline WC [41] & $89.9 \pm 12.6$ & $84.9 \pm 12.5$ & $93.8 \pm 11.3$ & $\begin{array}{l}< \\
0.001\end{array}$ \\
\hline $\mathrm{HC}[41]$ & $103.5 \pm 10.3$ & $99.3 \pm 9.6$ & $106.8 \pm 9.6$ & $\dot{0.001}$ \\
\hline $\mathrm{BMI}\left(\mathrm{kg} / \mathrm{m}^{2}\right)$ & $27.8 \pm 5.1$ & $25.50 \pm 4.74$ & $29.64 \pm 4.61$ & $\begin{array}{l}< \\
0.001\end{array}$ \\
\hline WHR & $0.86 \pm 0.07$ & $0.85 \pm 0.07$ & $0.88 \pm 0.06$ & 0.001 \\
\hline $\mathrm{TC}(\mathrm{mmol} / \mathrm{L})$ & $5.08 \pm 0.92$ & $4.94 \pm 0.90$ & $5.19 \pm 0.92$ & 0.028 \\
\hline $\mathrm{TG}(\mathrm{mmol} / \mathrm{L})$ & $1.47(1.01-2.00)$ & $1.26(0.86-1.84)$ & $1.61(1.17-2.19)$ & $\begin{array}{l}< \\
0.001\end{array}$ \\
\hline $\mathrm{HDL}-\mathrm{c}(\mathrm{mmol} / \mathrm{L})$ & $1.23(1.06-1.43)$ & $1.32(1.12-1.57)$ & $1.18(1.03-1.33)$ & $<.001$ \\
\hline LDL-c (mmol/L) & $2.77(2.34-3.37)$ & $2.62(2.19-3.18)$ & $2.85(2.56-3.44)$ & 0.001 \\
\hline UA & $376.84 \pm 87.95$ & $297.04 \pm 43.24$ & $438.91 \pm 58.95$ & $\begin{array}{l}< \\
0.001\end{array}$ \\
\hline Creatinine & $54.14 \pm 9.00$ & $52.29 \pm 8.33$ & $55.57 \pm 9.26$ & 0.004 \\
\hline eGFR & $145.60 \pm 29.80$ & $150.96 \pm 27.24$ & $141.44 \pm 31.12$ & 0.011 \\
\hline $\mathrm{T}(\mathrm{ng} / \mathrm{DL})$ & $\begin{array}{l}41.36(32.09- \\
53.46)\end{array}$ & $\begin{array}{l}40.21(32.22- \\
50.84)\end{array}$ & $\begin{array}{l}44.32(31.83- \\
56.34)\end{array}$ & 0.359 \\
\hline BFP & $37.36 \pm 7.34$ & $34.23 \pm 7.35$ & $39.57 \pm 6.51$ & $\begin{array}{l}< \\
0.001\end{array}$ \\
\hline VAl & $2.24(1.50-3.32)$ & $1.88(1.18-2.79)$ & $2.54(1.81-3.73)$ & $\begin{array}{l}< \\
0.001\end{array}$ \\
\hline
\end{tabular}


Table 2

Participant characteristics according to BMI category.

\begin{tabular}{|c|c|c|c|c|}
\hline & $\begin{array}{l}\text { Normal } \\
\mathrm{BMI}<24 \mathrm{~kg} / \mathrm{m}^{2}\end{array}$ & $\begin{array}{l}\text { Overweight } \\
24 \leq \mathrm{BMl}<28 \\
\mathrm{~kg} / \mathrm{m}^{2}\end{array}$ & $\begin{array}{l}\text { Obesity } \\
\text { BMI } \geq 28 \text { kg/m² }\end{array}$ & $\begin{array}{l}\mathbf{p} \\
\text { value }\end{array}$ \\
\hline $\mathrm{n}$ & $63(24.61 \%)$ & $66(25.78 \%)$ & $127(49.61 \%)$ & \\
\hline Age (years) & $29.0(26.0-31.0)$ & $26.0(23.0-30.0)$ & $27.0(24.0-31.0)$ & 0.039 \\
\hline Hyperuricemia $(\mathrm{n}, \%)$ & $14(5.5 \%)$ & $37(14.5 \%)$ & $93(36.3 \%)$ & $\begin{array}{l}< \\
0.001\end{array}$ \\
\hline $\begin{array}{l}\text { Occasional drinking (n, } \\
\%)\end{array}$ & $6(9.52 \%)$ & $1(1.51 \%)$ & $16(12.60 \%)$ & 0.035 \\
\hline SBP $(\mathrm{mmHg})$ & $113 \pm 9$ & $117 \pm 12$ & $122 \pm 13$ & $<.001$ \\
\hline $\mathrm{DBP}(\mathrm{mmHg})$ & $79 \pm 8$ & $79 \pm 10$ & $80 \pm 11$ & 0.387 \\
\hline WC [41] & $74.7 \pm 5.4$ & $87.0 \pm 5.5$ & $99.1 \pm 9.3$ & $\begin{array}{l}<.001 \\
0.001\end{array}$ \\
\hline $\mathrm{HC}[41]$ & $91.5 \pm 4.3$ & $100.5 \pm 5.1$ & $111.1 \pm 7.5$ & $\begin{array}{l}< \\
0.001\end{array}$ \\
\hline WHR & $0.81 \pm 0.05$ & $0.86 \pm 0.05$ & $0.89 \pm 0.07$ & $\begin{array}{l}< \\
0.001\end{array}$ \\
\hline $\mathrm{BMI}\left(\mathrm{kg} / \mathrm{m}^{2}\right)$ & $21.35 \pm 1.80$ & $26.07 \pm 1.16$ & $31.95 \pm 3.23$ & $\begin{array}{l}< \\
0.001\end{array}$ \\
\hline $\mathrm{TC}(\mathrm{mmol} / \mathrm{L})$ & $5.03 \pm 1.11$ & $4.92 \pm 0.81$ & $5.20 \pm 0.85$ & 0.118 \\
\hline $\mathrm{TG}(\mathrm{mmol} / \mathrm{L})$ & $1.06(0.76-1.69)$ & $1.40(1.00-2.02)$ & $1.59(1.25-2.31)$ & $\begin{array}{l}<.001 \\
0.001\end{array}$ \\
\hline HDL-c (mmol/L) & $1.46(1.17-1.66)$ & $1.18(1.07-1.34)$ & $1.20(1.03-1.33)$ & $\begin{array}{l}< \\
0.001\end{array}$ \\
\hline LDL-c (mmol/L) & $2.45(2.14-2.90)$ & $2.77(2.30-3.36)$ & $2.91(2.60-3.46)$ & $\begin{array}{l}< \\
0.001\end{array}$ \\
\hline SUA ( $\mu \mathrm{mol} / \mathrm{L})$ & $312.60 \pm 71.16$ & $372.57 \pm 84.86$ & $410.93 \pm 78.76$ & $\dot{0} 001$ \\
\hline Creatinine $(\mu \mathrm{mol} / \mathrm{L})$ & $52.76 \pm 8.01$ & $53.99 \pm 7.99$ & $54.89 \pm 9.88$ & 0.309 \\
\hline eGFR $\left(\mathrm{mL} / \mathrm{min} / 1.73 \mathrm{~m}^{2}\right)$ & $148.23 \pm 27.35$ & $145.80 \pm 27.10$ & $144.22 \pm 32.30$ & 0.685 \\
\hline $\mathrm{T}(\mathrm{ng} / \mathrm{dL})$ & $\begin{array}{l}42.04(33.69- \\
55.83)\end{array}$ & $\begin{array}{l}40.16(32.10- \\
56.74)\end{array}$ & $\begin{array}{l}41.55(31.08- \\
53.39)\end{array}$ & 0.654 \\
\hline BFP (\%) & $27.20 \pm 4.45$ & $35.02 \pm 2.58$ & $42.48 \pm 4.75$ & $<.001$ \\
\hline
\end{tabular}




\begin{tabular}{|lllll|}
\hline & Normal & $\begin{array}{l}\text { Overweight } \\
\mathbf{2 4} \leq \mathrm{BMI}<\mathbf{2 8} \\
\mathrm{kg} / \mathbf{m}^{2}\end{array}$ & $\begin{array}{l}\text { Obesity } \\
\mathrm{BMI} \mathbf{2 8} \mathbf{~ k g} / \mathrm{m}^{2}\end{array}$ & $\begin{array}{l}\text { value } \\
\text { VAl }\end{array}$ \\
\hline $1.45(0.86-2.08)$ & $2.19(1.42-3.46)$ & $2.65(1.93-3.77)$ & $<$ \\
\hline
\end{tabular}

\section{Characteristics Of Study Population}

The detailed anthropometric and metabolic characteristics of females with PCOS categorized by the existence of hyperuricemia were shown in Table 1. Compared with the normouricemia group, the group with hyperuricemia had significantly greater values for SBP (116 \pm 11 vs. $120 \pm 13, P=0.013), T C(4.94 \pm$ 0.90 vs. $5.19 \pm 0.92, p=0.028)$, TG (1.26 [0.86-1.84] vs. 1.61 [1.17-2.19], $P<0.001)$, LDL-c (2.62 [2.193.18 ] vs. $2.85[2.56-3.44], P=0.001)$, and creatinine $(52.29 \pm 8.33$ vs. $55.57 \pm 9.26, p=0.004)$ and lower values for HDL-c (1.32 [1.12-1.57] vs. 1.18 [1.03-1.33], $P<0.001)$ and eGFR $(150.96 \pm 27.74$ vs. $141.44 \pm$ $31.12, p=0.011)$. The obesity indices such as BMI $(25.50 \pm 4.74$ vs. $29.64 \pm 4.61, P<0.001)$, WHR $(0.85 \pm$ 0.07 vs. $0.88 \pm 0.06, P=0.001)$, WC ( $84.9 \pm 12.5$ vs. $93.8 \pm 11.3, P<0.001), H C(99.3 \pm 9.6$ vs. $106.8 \pm 9.6, P$ $<0.001), B F P(34.23 \pm 7.35$ vs. $39.57 \pm 6.51, P<0.001)$ and $\operatorname{VAl}(1.88(1.18-2.79)$ vs. $2.54(1.81-3.73), P$ $<0.001)$ ) were higher in the hyperuricemia group than that in the normouricemia group. However, there was no significant differences in age, DBP, and T between two groups.

Besides, in order to further study the relationship between obesity and other indicators, subjects were categorized into three groups (normal weight, overweight and obesity) in Table 2. As the degree of obesity increased, the level of SUA $(312.6 \pm 71.16,372.57 \pm 84.86,410.93 \pm 78.76$, respectively, $p<0.001)$ and the prevalence rate of hyperuricemia also increased $(p<0.001)$. In addition, subjects with higher BMI were more likely to be older and occasional smoker and had significantly higher levels of SBP, WC, HC, WHR, BFP, VAI (1.45 (0.86-2.08), 2.19 (1.42-3.46), 2.65 (1.93-3.77), $P<0.001$, respectively), TG, HDL-C and LDL-c. However, there was no significant difference in DBP, TC, creatinine, eGFR and T.

Figure 1 showed the distributions of SUA levels and prevalence of hyperuricemia according to tertiles of VAl in patients with PCOS. As the tertiles of VAl increased, the level of SUA $(p<0.001)$ and the prevalence rate of hyperuricemia also increased $(2.6 \%, 21.3 \%, 22.4 \%$, respectively, $p<0.001)$.

\section{Correlations Of Sua Level With Clinical Characteristics}

We performed Pearson's correlation to investigate the correlation between SUA with clinical characteristics. We found that there were significant association between the obesity indexes (BMI, BFP and WHR), lipid profiles (log (TG), log (LDL-c) and log (HDL-c)), SBP, and $\log (\mathrm{VAI})(r=0.346, p<0.001)$ with SUA. However, further stepwise linear regression analysis indicated that SUA level were only 
positively associated with BMI $(\beta=0.325, p<0.001)$ and $\log (\mathrm{VAI})(\beta=0.243, p<0.001)$ in PCOS women (Table 3).

Table 3

Pearson's correlation and stepwise linear regression of determinants of serum uric acid

\begin{tabular}{|c|c|c|c|c|}
\hline \multirow[b]{2}{*}{ Variables } & \multicolumn{2}{|c|}{ Pearson's correlation } & \multicolumn{2}{|c|}{ Stepwise linear regression } \\
\hline & $r$ & $\mathrm{p}$ value & Standardized $\beta$ & $p$ value \\
\hline Age (years) & -0.034 & 0.591 & - & \\
\hline $\mathrm{SBP}(\mathrm{mmHg})$ & 0.229 & $<0.001$ & - & \\
\hline $\mathrm{DBP}(\mathrm{mmHg})$ & 0.102 & 0.104 & - & \\
\hline BMI $\left(\mathrm{kg} / \mathrm{m}^{2}\right)$ & 0.438 & $<0.001$ & 0.325 & $<0.001$ \\
\hline WHR & 0.278 & $<0.001$ & - & \\
\hline TC & 0.116 & 0.065 & - & \\
\hline $\log (T G)$ & 0.285 & $<0.001$ & - & \\
\hline $\log (\mathrm{HDL}-\mathrm{C})$ & -0.294 & $<0.001$ & - & \\
\hline $\log ($ LDL-C) & 0.193 & 0.002 & - & \\
\hline $\log (T)$ & 0.008 & 0.907 & - & \\
\hline BFP & 0.406 & $<0.001$ & & \\
\hline Log (VAI) & 0.346 & $<0.001$ & 0.243 & $<0.001$ \\
\hline
\end{tabular}

\section{Association Of Vai And Sua Level}

In addition, multivariate linear logistic regression analysis was used to further assess the association between VAI and SUA level (Table 4). In model 1 with adjustment for age and occasional drinking, VAI was significantly associated with SUA level, and the coefficient $(95 \% \mathrm{Cl})$ was $16.52(10.18-22.85, \mathrm{P}<$ 0.001). In model 2 with further adjustment for SBP, DBP, and eGFR, the significant association of VAI with SUA level remained and the coefficient $(95 \% \mathrm{Cl})$ was $14.74(8.45-21.03, \mathrm{P}<0.001)$. Further, after adjusted for additional TC, LDL-C, T, and BMI in model 3 , VAI was still significantly associated with the SUA level, and the coefficient $(95 \% \mathrm{Cl})$ was $9.20(2.85-15.56, \mathrm{P}=0.005)$. 
Table 4

Associations of visceral adiposity index and body fat percentage with serum uric acid level and hyperuricemia in patients with PCOS.

\begin{tabular}{|c|c|c|c|c|c|c|}
\hline & \multicolumn{3}{|c|}{$\begin{array}{l}\text { Multivariable Linear regression on serum uric acid } \\
\text { level }\end{array}$} & \multicolumn{3}{|c|}{$\begin{array}{l}\text { Logistic regression on } \\
\text { hyperuricemia }\end{array}$} \\
\hline & Coefficient & $95 \% \mathrm{Cl}$ & $P$ value & ORs & $95 \% \mathrm{Cl}$ & $P$ value \\
\hline \multicolumn{7}{|l|}{ VAl } \\
\hline $\begin{array}{l}\text { Model } \\
1\end{array}$ & 16.52 & $10.18-22.85$ & $<0.001$ & 1.56 & $1.26-1.92$ & $<0.001$ \\
\hline $\begin{array}{l}\text { Model } \\
2\end{array}$ & 14.74 & $8.45-21.03$ & $<0.001$ & 1.53 & $1.24-1.89$ & $<0.001$ \\
\hline $\begin{array}{l}\text { Model } \\
3\end{array}$ & 9.20 & $2.85-15.56$ & 0.005 & 1.32 & $1.05-1.65$ & 0.018 \\
\hline \multicolumn{7}{|c|}{ Model 1 was adjusted for age, occasional drinking. } \\
\hline \multicolumn{7}{|c|}{ Model 2 was further adjusted for SBP, DBP, and eGFR } \\
\hline Model 3 & was further ac & for TC, LDL-C, & d BMI & & & \\
\hline
\end{tabular}

\section{Association Of Vai And Hyperuricemia}

Multivariate logistic regression analysis was performed to explore the association between VAI and hyperuricemia. The following three models were performed with same adjustments as those in multivariable linear regression analyses. In model 1, VAI were significantly associated with hyperuricemia, and the adjusted OR $(95 \% \mathrm{Cl})$ was $1.56(1.26-1.92, \mathrm{P}<0.001)$. In model 2 , the associations of VAl with hyperuricemia remained significant, with the adjusted OR $(95 \% \mathrm{Cl})$ of $1.53(1.24-1.89, \mathrm{P}<0.001)$. In model 3 , the significant associations between VAl and hyperuricemia still existed, and the adjusted OR $(95 \% \mathrm{Cl})$ was $1.32(1.05-1.65, \mathrm{P}=0.018)($ Table 4$)$.

\section{Discussion}

In the present study, the prevalence of hyperuricemia was $56.3 \%$ in PCOS women. The obesity indices such as BMI, WHR, WC, HC, BFP and VAI in PCOS women with hyperuricemia were significantly higher than those in normouricemia patients. Stepwise linear regression analysis showed that only BMI and VAI were significantly and positively associated with SUA level. Furthermore, VAI was significantly associated with hyperuricemia after adjusting for potential confounding factors including $\mathrm{BMI}$ in multivariable linear regression and logistic regression analyses. Additionally, SUA level and the prevalence of hyperuricemia increased along with tertiles of VAI in women with PCOS.

Previous studies have shown increasing SUA levels were positively associated with increased cardiovascular mortality and increased the risk of adverse pregnancy outcomes in PCOS patients, 
therefore SUA level determination is valuable for women with PCOS[15, 25]. Several studies had reported that the SUA levels and prevalence of hyperuricemia increased greatly in obese PCOS women[13], which was similar to our results. However, the underlying mechanism had not been clear until now, there were some hypotheses as following: body fat accelerated SUA production and the synthesis of triglyceride[26] and hyperinsulinemia could decrease renal UA excretion[27]. Since as derivatives of purine inhibiting oocyte maturation[28, 29], the elevated SUA levels in patients with PCOS could further aggravate the adverse pregnancy outcome. Besides, some guidelines have emphasized the benefits of weight loss in overweight or obese population with hyperuricemia $[4,30]$. Therefore, more attention should be paid on women with high level of SUA, especially in obese PCOS women. To our knowledge, this is the first crosssectional study to comprehensively evaluate the relationship between six obesity indicators $(\mathrm{WC}, \mathrm{HC}, \mathrm{BMI}$, WHR, BFP, VAI) and hyperuricemia in PCOS women.

Obesity, especially visceral obesity not only aggravates reproductive outcomes in patients with PCOS, but also accelerates progression of cardiovascular disease and cardiovascular events[31]. Moreover, visceral obesity leads to IR and compensatory hyperinsulinemia by impairing the action of insulin, which plays a major role in the pathophysiological process of PCOS[32]. Therefore, to future evaluate and treat metabolic and reproductive disorders in women with PCOS it is critical to determine whether visceral obesity is independent of overall obesity. Although the gold standard for evaluating visceral fat accumulation is magnetic resonance imaging (MRI) and computed tomography (CT)[33]. However, considering the cost of MRI and radiation exposure, some newly developed indicators such as VAI has been introduced [34]. In recent years, VAl as surrogate marker of visceral fat dysfunction have been widely used in clinical practice and it is independently correlated with cardio-metabolic risk in the general population[35]. Recent study indicated that as VAI levels increased, the severity of anovulation, IR, dyslipidemia and the risk of type 2 diabetes also increased along with in PCOS patients[36-38]. Further Oh et al. [39] reported that VAI could replace visceral CT scanning to evaluate visceral adiposity and could predict IR in young PCOS patients, and also determined that VAI >1.79 was the optimal cutoff point for visceral adiposity. A recent cross-sectional study of 1328 general population showed that visceral fat accumulation was positively correlated with the risk of hyperuricemia[40]. Similarly, the results in the current study also suggested that VAl, as an indicator of visceral adipose accumulation, was a significant risk factor of hyperuricemia in patients with PCOS independent of potential confounding factors, which was consistent with the study conducted by Huang et al. [40]. Also, we observed that the prevalence of hyperuricemia trended to increase with the elevation of VAl in PCOS women. Overall, VAl appears to provide more valuable information beyond other obesity indices in assessing the SUA level and may be used as a potential risk marker for hyperuricemia in PCOS women.

The major advantage of our study was that it comprehensively evaluated the associations of various obesity indices with hyperuricemia in women with PCOS for the first time, and to further determine the relationship between VAI and SUA level and hyperuricemia. However, there were also several limitations to the present study. First, being a cross-sectional study, these data could not determine the causal relationship between VAl and hyperuricemia. The second limitation was that our sample size was relatively small and might not have enough power to reflect a significant correlation between VAI and the 
SUA level, which calls for further verification in larger PCOS samples. Third, we did not evaluate visceral fat by more accurate methods such as CT or MRI. Therefore, it remains to develop a well-designed epidemiological study to explore the predictive value of VAl for hyperuricemia in PCOS women and to determine its pathogenesis.

\section{Conclusion}

In summary, the present study indicates that VAI was independently associated with hyperuricemia, even with adjustment for BMI and other potential confounding factors. Therefore, VAI could be used as a potential hyperuricemia risk marker in PCOS women, beyond the general index of obesity.

\section{Abbreviations}

PCOS, Polycystic ovary syndrome; IR, insulin resistance; BFP, body fat percentage; CVDs, Cardiovascular diseases; T2DM, Type 2 Diabetes Mellitus; BP, blood pressure; SD, standard deviation; IQR, inter-quartile range; $\mathrm{Cl}$, confidence interval; $\mathrm{MRI}$, magnetic resonance imaging; $\mathrm{CT}$, computed tomography; SBP, systolic pressure; DBP, diastolic pressure; $\mathrm{BMI}$, body mass index; $\mathrm{WC}$, waist circumference; $\mathrm{HC}$, hip circumference; WHR, waist-to-hip ratio; VAl, visceral adiposity index; BFP, body fat percentage; TC, total cholesterol; TG, triglycerides; HDL-c, high density lipoprotein cholesterol; LDL-c, low density lipoprotein cholesterol; eGFR, estimated glomerular filtration rate; T, testosterone; SUA, serum uric acid.

\section{Declarations}

\section{Acknowledgements}

We are grateful to all the subjects for their participation.

\section{Author Contributions}

The study concept and design were framed by $C L$ and $X Y$. CY, YH, HY, XZ, JY, DM, ZC, and XZ collected data. $\mathrm{CY}, \mathrm{YH}$ and $\mathrm{CL}$ conducted the statistical data analysis and drafted the manuscript. $\mathrm{XY}, \mathrm{CL}$ and $\mathrm{XY}$ contributed to discussion and revision. All authors read and approved the final manuscript.

\section{Funding Information}

CL was founded by Natural Science Foundation of Fujian Province (NO. 2020J011242), Natural Science Foundation of China grant (No. 81870611) and Open project of State Key Laboratory of Cellular Stress Biology, Xiamen University (No. SKLCSB2019KF004). HY was founded by Xiamen Municipal Bureau of Science and Technology (No. 3502Z20174068) and the First Affiliated Hospital of Xiamen University (No. XYY2016002).

\section{Conflict of Interest}


The authors declare that they have no conflict of interest.

\section{Ethical Approval}

All procedures performed in studies involving human participants were in accordance with the ethical standards of the institutional and/or national research committee and with the Helsinki declaration and its later amendments or comparable ethical standards.

\section{References}

1. Borruel S, Fernandez-Duran E, Alpanes M, Marti D, Alvarez-Blasco F, Luque-Ramirez M, EscobarMorreale HF: Global adiposity and thickness of intraperitoneal and mesenteric adipose tissue depots are increased in women with polycystic ovary syndrome (PCOS).J Clin Endocrinol Metab 2013, 98:1254-1263.

2. Azziz R, Carmina E, Chen Z, Dunaif A, Laven JS, Legro RS, Lizneva D, Natterson-Horowtiz B, Teede HJ, Yildiz BO: Polycystic ovary syndrome.Nat Rev Dis Primers 2016, 2:16057.

3. Yildiz BO, Knochenhauer ES, Azziz R: Impact of obesity on the risk for polycystic ovary syndrome.J Clin Endocrinol Metab 2008, 93:162-168.

4. Qaseem A, Harris RP, Forciea MA: Management of Acute and Recurrent Gout: A Clinical Practice Guideline From the American College of Physicians.Ann Intern Med 2017, 166:58-68.

5. Zimmet P, Magliano D, Matsuzawa Y, Alberti G, Shaw J: The metabolic syndrome: a global public health problem and a new definition.J Atheroscler Thromb 2005, 12:295-300.

6. Goodpaster BH, Krishnaswami S, Harris TB, Katsiaras A, Kritchevsky SB, Simonsick EM, Nevitt M, Holvoet $\mathrm{P}$, Newman AB: Obesity, regional body fat distribution, and the metabolic syndrome in older men and women.Arch Intern Med 2005, 165:777-783.

7. Roriz AK, Passos LC, de Oliveira CC, Eickemberg M, Moreira Pde A, Sampaio LR: Evaluation of the accuracy of anthropometric clinical indicators of visceral fat in adults and elderly.PLOS One 2014, 9:e103499.

8. Grossman DC, Bibbins-Domingo K, Curry SJ, Barry MJ, Davidson KW, Doubeni CA, Epling JW, Jr., Kemper AR, Krist AH, Kurth AE, et al: Screening for Obesity in Children and Adolescents: US Preventive Services Task Force Recommendation Statement.Jama 2017, 317:2417-2426.

9. Nusrianto R, Ayundini G, Kristanti M, Astrella C, Amalina N, Muhadi, Riyadina W, Tahapary DL, Soewondo P: Visceral adiposity index and lipid accumulation product as a predictor of type 2 diabetes mellitus: The Bogor cohort study of non-communicable diseases risk factors.Diabetes Res Clin Pract 2019, 155:107798.

10. Ahn N, Baumeister SE, Amann U, Rathmann W, Peters A, Huth C, Thorand B, Meisinger C: Visceral adiposity index (VAI), lipid accumulation product (LAP), and product of triglycerides and glucose (TyG) to discriminate prediabetes and diabetes.Sci Rep 2019, 9:9693. 
11. Mazidi M, Kengne AP, Katsiki N, Mikhailidis DP, Banach M: Lipid accumulation product and triglycerides/glucose index are useful predictors of insulin resistance.J Diabetes Complications 2018, 32:266-270.

12. Chen MY, Zhao CC, Li TT, Zhu Y, Yu TP, Bao YQ, Li LX, Jia WP: Serum uric acid levels are associated with obesity but not cardio-cerebrovascular events in Chinese inpatients with type 2 diabetes.Sci Rep 2017, 7:40009.

13. Mu L, Pan J, Yang L, Chen Q, Chen Y, Teng Y, Wang P, Tang R, Huang X, Chen X, Yang H: Association between the prevalence of hyperuricemia and reproductive hormones in polycystic ovary syndrome.Reprod Biol Endocrinol 2018, 16:104.

14. Hayden MR, Tyagi SC: Uric acid: A new look at an old risk marker for cardiovascular disease, metabolic syndrome, and type 2 diabetes mellitus: The urate redox shuttle.Nutr Metab (Lond) 2004, 1:10.

15. Hawkins TL, Roberts JM, Mangos GJ, Davis GK, Roberts LM, Brown MA: Plasma uric acid remains a marker of poor outcome in hypertensive pregnancy: a retrospective cohort study.Bjog 2012, 119:484492.

16. Yarali H, Yildirir A, Aybar F, Kabakci G, Bukulmez O, Akgul E, Oto A: Diastolic dysfunction and increased serum homocysteine concentrations may contribute to increased cardiovascular risk in patients with polycystic ovary syndrome.Fertil Steril 2001, 76:511-516.

17. Anttila L, Rouru J, Penttilä T, Irjala K: Normal serum uric acid concentrations in women with polycystic ovary syndrome. Hum Reprod 1996, 11:2405-2407.

18. Revised 2003 consensus on diagnostic criteria and long-term health risks related to polycystic ovary syndrome. Fertil Steril 2004, 81:19-25.

19. Chen Y, Zheng X, Ma D, Zheng S, Han Y, Su W, Liu W, Xiao F, Lin M, Yan X, et al: Neck circumference is a good predictor for insulin resistance in women with polycystic ovary syndrome. Fertil Steril 2020.

20. Browning LM, Mugridge O, Dixon AK, Aitken SW, Prentice AM, Jebb SA: Measuring abdominal adipose tissue: comparison of simpler methods with MRI.Obes Facts 2011, 4:9-15.

21. Zheng S, Tong M, Dong L, Du C, Zheng X, Wang L, Huang P, Liu W, Lin M, Liu C: Lipid accumulation product independently correlate with hepatic steatosis quantified by controlled attenuation parameter in women with polycystic ovary syndrome.Endocr Connect 2020, 9:154-162.

22. Lin M, Liu C, Liu Y, Wang D, Zheng C, Shi X, Chen Z, Liu J, Li X, Yang S, Li Z: Fetuin-B Links Nonalcoholic Fatty Liver Disease to Chronic Kidney Disease in Obese Chinese Adults: A CrossSectional Study.Ann Nutr Metab 2019, 74:287-295.

23. Hamburger M, Baraf HS, Adamson TC, 3rd, Basile J, Bass L, Cole B, Doghramji PP, Guadagnoli GA, Hamburger $F$, Harford R, et al: 2011 Recommendations for the diagnosis and management of gout and hyperuricemia.Postgrad Med 2011, 123:3-36.

24. Zhou B: [Predictive values of body mass index and waist circumference to risk factors of related diseases in Chinese adult population].Zhonghua Liu Xing Bing Xue Za Zhi 2002, 23:5-10. 
25. Fang J, Alderman MH: Serum uric acid and cardiovascular mortality the NHANES I epidemiologic follow-up study, 1971-1992. National Health and Nutrition Examination Survey.Jama 2000, 283:2404-2410.

26. Maglio C, Peltonen M, Neovius M, Jacobson P, Jacobsson L, Rudin A, Carlsson LM: Effects of bariatric surgery on gout incidence in the Swedish Obese Subjects study: a non-randomised, prospective, controlled intervention trial.Ann Rheum Dis 2017, 76:688-693.

27. Marinello E, Leoncini R, Terzuoli L, Vannoni D, Porcelli B, Resconi G: Effect of testosterone on purine nucleotide metabolism in rat liver.Horm Metab Res 2004, 36:614-619.

28. Wen X, Perrett D, Jones N, Tozer AJ, Docherty SM, lles RK: High follicular fluid adenosine levels may be pivotal in the metabolism and recycling of adenosine nucleotides in the human follicle.Metabolism 2010, 59:1145-1155.

29. Lavy G, Behrman HR, Polan ML: Purine levels and metabolism in human follicular fluid. Hum Reprod 1990, 5:529-532.

30. Hamburger M, Baraf HS, Adamson TC, 3rd, Basile J, Bass L, Cole B, Doghramji PP, Guadagnoli GA, Hamburger $F$, Harford R, et al: 2011 recommendations for the diagnosis and management of gout and hyperuricemia.Phys Sportsmed 2011, 39:98-123.

31. Cascella T, Palomba S, De Sio I, Manguso F, Giallauria F, De Simone B, Tafuri D, Lombardi G, Colao A, Orio F: Visceral fat is associated with cardiovascular risk in women with polycystic ovary syndrome. Hum Reprod 2008, 23:153-159.

32. Vilmann LS, Thisted E, Baker JL, Holm JC: Development of obesity and polycystic ovary syndrome in adolescents. Horm Res Paediatr 2012, 78:269-278.

33. Alberti KG, Zimmet P, Shaw J: Metabolic syndrome-a new world-wide definition. A Consensus Statement from the International Diabetes Federation.Diabet Med 2006, 23:469-480.

34. Jabłonowska-Lietz B, Wrzosek M, Włodarczyk M, Nowicka G: New indexes of body fat distribution, visceral adiposity index, body adiposity index, waist-to-height ratio, and metabolic disturbances in the obese.Kardiol Pol 2017, 75:1185-1191.

35. Moran LJ, Misso ML, Wild RA, Norman RJ: Impaired glucose tolerance, type 2 diabetes and metabolic syndrome in polycystic ovary syndrome: a systematic review and meta-analysis. Hum Reprod Update 2010, 16:347-363.

36. Ehsani B, Moslehi N, Mirmiran P, Ramezani Tehrani F, Tahmasebinejad Z, Azizi F: A visceral adiposity index-related dietary pattern and the cardiometabolic profiles in women with polycystic ovary syndrome.Clin Nutr 2016, 35:1181-1187.

37. Poirier P, Giles TD, Bray GA, Hong Y, Stern JS, Pi-Sunyer FX, Eckel RH: Obesity and cardiovascular disease: pathophysiology, evaluation, and effect of weight loss: an update of the 1997 American Heart Association Scientific Statement on Obesity and Heart Disease from the Obesity Committee of the Council on Nutrition, Physical Activity, and Metabolism.Circulation 2006, 113:898-918.

38. Tchernof A, Després JP: Pathophysiology of human visceral obesity: an update.Physiol Rev 2013, 93:359-404. 
39. Oh JY, Sung YA, Lee HJ: The visceral adiposity index as a predictor of insulin resistance in young women with polycystic ovary syndrome.Obesity (Silver Spring) 2013, 21:1690-1694.

40. Huang $X$, Jiang $X$, Wang $L$, Chen $L$, Wu $Y$, Gao $P$, Hua F: Visceral adipose accumulation increased the risk of hyperuricemia among middle-aged and elderly adults: a population-based study.J Trans/ Med 2019, 17:341.

41. Lim S, Smith CA, Costello MF, MacMillan F, Moran L, Ee C: Barriers and facilitators to weight management in overweight and obese women living in Australia with PCOS: a qualitative study.BMC Endocr Disord 2019, 19:106.

\section{Figures}
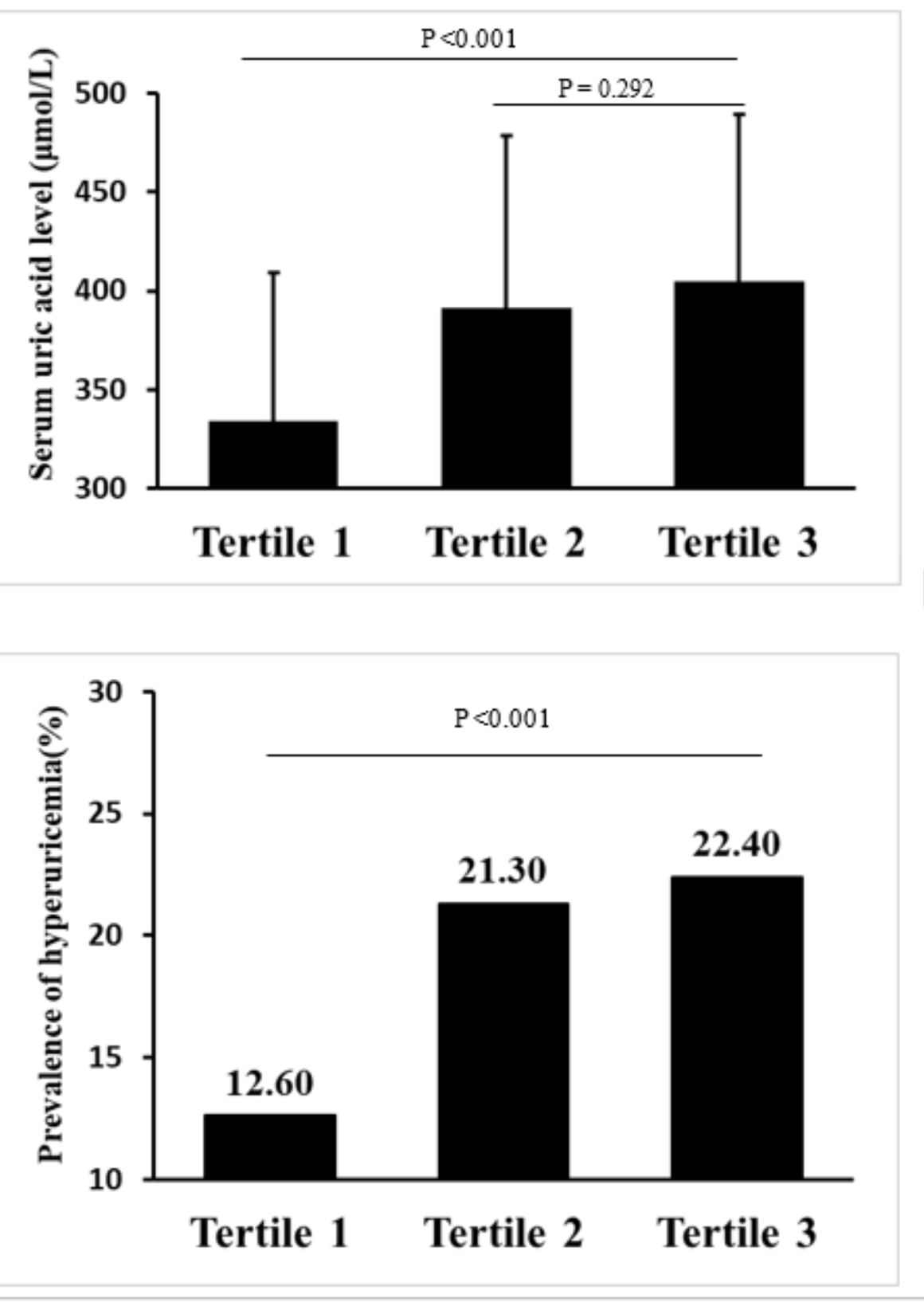

Figure 1 
Distributions of serum uric acid levels stratified by VAI tertiles and prevalence of hyperuricemia in patients with PCOS. Abbreviations: PCOS, Polycystic ovary syndrome; VAl, visceral adiposity index; 